\title{
Tradeoff in the supply and demand for CO 2 dominates the divergence of net photosynthesis rates of functional plants in alpine ecosystems
}

\author{
Hongyun Yao ${ }^{1}$, Xiao-Yan Li $^{1}$, Cicheng Zhang ${ }^{2}$, Pei Wang ${ }^{1}$, Fangzhong Shi ${ }^{1}$, and Yujing \\ Deng $^{1}$ \\ ${ }^{1}$ Beijing Normal University \\ ${ }^{2}$ Hunan Normal University
}

November 11, 2021

\begin{abstract}
As regional heterogeneity on the Qinghai Tibetan Plateau (QTP), the "greening rate" between alpine steppe in the west and alpine meadow ecosystems in the east is difference during the past several decades. To investigate the difference, the net photosynthetic rate (An) and the supply (mesophyll conductance $(g \mathrm{~m})$, stomatal conductance $(g$ s $))$ and demand (the maximum rates of Rubisco carboxylase activity $\left(V_{\text {cmax }}\right)$ and photosynthetic electron transport $\left.\left(J_{\max }\right)\right)$ for $\mathrm{CO} 2$ of three plants functional types (PFTs) were measured. Other functional traits and influencing factors were compared among ecosystems along the altitudinal gradients of QTP. The An of the PFTs was simulated under potential future conditions. At high altitudes, grass was found to maintain a relatively stable An by decreasing $V_{\mathrm{cmax}}, J_{\max }$, and $g_{\mathrm{s}}$, while slightly increasing $g \mathrm{~m}$, compared with that at a low altitude. The An of sedge and shrubs increased with rising $V$ cmax,$J \max$ and $g \mathrm{~s}$ and $g$ m values, resulting in a large increment in the An at low altitudes. Grass seemed to be less sensitive to the environment by reducing the supply of and holding onto $\mathrm{CO}_{2}$, while sedge and shrub increased both. Grass and sedge should be divided into two PFTs rather than remaining as one based on their opposite physiological and morphological functions in response to climate change. The ecosystem at $3600 \mathrm{~m}$ was transitional. $C$ a was likely to be a more dominant factor than $T$ a in affecting the An of grass. The order of rising An in PFTs was shrub > sedge > grass and the An of alpine meadow was found to increase more under the two future climate scenarios.
\end{abstract}

\section{Hosted file}

Main Manuscript.docx available at https://authorea.com/users/445631/articles/545105-tradeoffin-the-supply-and-demand-for-co-2-dominates-the-divergence-of-net-photosynthesis-ratesof-functional-plants-in-alpine-ecosystems 